\title{
In Vitro Growth, Morphogenesis, and Acclimatization of Endangered Rindera umbellata (Waldst. \& Kit.) Bunge
}

\author{
Marija Perić \\ Institute of Botany and Garden, Faculty of Biology, University of Belgrade, \\ Takovska 43, 11000 Belgrade, Serbia
}

Slavica Dmitrović, Suzana Živković, Biljana Filipović, Marijana Skorić,
Ana Simonović, and Slađana Todorović1
Department for Plant Physiology, Institute for Biological Research "Siniša
Stankovic'," University of Belgrade, Bul. Despota Stefana 142, 11000
Belgrade, Serbia

Additional index words. immature embryos, tissue culture, acclimatization, sucrose, fructose, glucose, Boraginaceae

\begin{abstract}
Rindera umbellata (Waldst. \& Kit.) Bunge is a rare, critically endangered and horticulturally appealing plant with unexplored pharmaceutical potential. Its distribution is restricted to sandy habitats, whereas propagation in nature is limited by fungal infections of the seeds. To initiate its ex situ conservation and provide material for metabolomic studies, we have introduced $R$. umbellata into in vitro culture using immature embryos as primary explants. A $72 \%$ of the embryos germinated on growth regulator-free medium. The optimization of growth conditions was based on varying carbohydrates (sucrose, glucose, and fructose) in the medium. In vitro growth and development of $R$. umbellata plants were significantly affected by both the type and concentration of the applied sugars. For most recorded parameters, including leaf elongation, biomass production, rooting percentage, and the number and length of roots, $0.1 \mathrm{~m}$ sucrose was optimal. The highest percentage of explants with developed buds was achieved on $0.06 \mathrm{M}$ sucrose $(38.77 \%)$ or 0.3 m glucose $(27.43 \%)$. The plantlets obtained on 0.1 м sucrose were successfully acclimatized to greenhouse and field conditions with survival rates of $71.43 \%$ and $42.86 \%$, respectively. To our best knowledge, this is the first publication dedicated to this species.
\end{abstract}

Rindera umbellata (Waldst. \& Kit.) Bunge, also known as Mattia umbellata (Waldst. \& Kit.) Schult. or Cynoglossum umbellatum (Waldst. \& Kit.), belongs to the Boraginaceae family and is a biennial to perennial herbaceous plant. Numerous hairy leaves are set in a rosette (Fig. 1A). During flowering, ribbed and hairy stems may grow up to $60 \mathrm{~cm}$ in height, to be crowned with beautiful inflorescences with bronze, amber, or apricot flowers (Fig. 1A-B). Being a psammophyte, $R$. umbellata distribution is limited to sandy habitats. In Serbia, R. umbellata is found in Deliblato and Kladovo Sands, specifically in Chrysopogonetum pannonicum plant association. As a naturally rare and critically endangered species, $R$. umbellata is under State Protection Legislation (Diklić et al., 1999). Propagation of $R$. umbellata in nature is limited by fungal infections and insufficient seed maturity (Ljaljević Grbić et al., 2005). A literature search revealed no publications dedicated to this rare, endangered and horticulturally

Received for publication 30 Mar. 2012. Accepted for publication 18 Apr. 2012.

This work was supported by grant No. 173024 of Serbian Ministry of Education and Science.

${ }^{1}$ To whom reprint requests should be addressed; e-mailslatod@ibiss.bg.ac.rs. appealing species with unexplored pharmaceutical potential. Nothing is known about R. umbellata secondary metabolites, but many related Boraginaceae species produce valued pharmaceuticals (Papageorgiou et al., 2008).

It is well known that plants grown in vitro have reduced photosynthetic activity as a result of low light intensity, limited gas exchange, and high relative humidity, so carbohydrates are a necessary component of culture media (Kozai, 1991; Murashige and Skoog, 1962). However, carbohydrates are not only a fuel for plant growth, but also regulatory and signaling molecules that control plant development from germination and vegetative growth to reproductive development and seed formation (Mohamed and Alsadon, 2010; Rolland et al., 2006; Smeekens, 2000; Todorović et al., 2006). Sugars are also osmotic agents that regulate the uptake of other medium constituents and consequently the course of in vitro culture (Nowak et al., 2004; Sghaier et al., 2009). Although common sugars are readily interconvertible in plant cells, the nutritional requirements nevertheless vary among plant species. Among carbohydrates used for in vitro cultures, sucrose is the most common, but for some species, other sugars are more suitable. Glucose proved to be a better carbon source for in vitro development of Nepeta rtanjensis (Mišić et al., 2005) as well as for tissue cultures of some woody plants, including Corylus avelana (Yu and Reed, 1993), Quercus suber (Romano et al., 1995), and Prunus mume (Harada and Murai, 1996). Compared with sucrose, glucose and fructose are better carbon sources for two Fagus species (Cuenca and Vieitez, 2000). In some cases fructose proved to be more efficient than other carbohydrates (Welander et al., 1989). Thus, the optimization of a protocol for in vitro propagation of an unexplored plant species inevitably includes variations of carbohydrate components in the growth medium.

We present the introduction of $R$. umbellata into tissue culture and optimization of the protocol for its in vitro growth and organogenesis by varying carbohydrate source (sucrose, glucose, and fructose) and concentration in the medium followed by a protocol for acclimatization to greenhouse and field conditions. In vitro propagation of $R$. umbellata would be a solution not only for its protection by ex situ conservation, but also to obtain material for planned metabolomic analyses.

\section{Materials and Methods}

Plant material and the establishment of in vitro cultures. $R$. umbellata embryos excised from immature seeds were used as primary explants for the establishment of in vitro cultures. The seeds were collected from a single plant, found in a small population in Deliblato Sands, in June 2006 (Fig. 1A). The seeds were rinsed in tap water for $30 \mathrm{~min}$, surface-sterilized for 5 to $10 \mathrm{~min}$ in $50 \%$ commercial bleach, and then rinsed five times in sterile water. The embryos were germinated on basal medium containing Murashige and Skoog (MS) salts and vitamins (Murashige and Skoog, 1962), $3 \%$ sucrose, and $0.7 \%$ agar. For further development, 10 -d-old seedlings were transferred to erlenmeyer flasks with the same medium. To support the formation of adventitious buds, stem explants were placed on solid MS medium containing $0.1 \mathrm{M}$ sucrose, $1 \mathrm{mg} \cdot \mathrm{L}^{-1}$ 6-benzylaminopurine (BAP) and $0.5 \mathrm{mg} \cdot \mathrm{L}^{-1}$ indole-3-acetic acid (IAA). The obtained adventitious buds were used for further propagation on the same medium. Before autoclaving the media $\left(25 \mathrm{~min}\right.$ at $\left.114^{\circ} \mathrm{C}\right)$, the $\mathrm{pH}$ was adjusted to 5.8. For all experiments the plant cultures were grown in a growth room under a 16/8-h (day/night) photoperiod under a photon flux rate of $32.5 \mu \mathrm{mol} \cdot \mathrm{m}^{-2} \cdot \mathrm{s}^{-1}$ at the level of the samples at $25 \pm 2{ }^{\circ} \mathrm{C}$.

Experimental design. To study the influence of the carbohydrate source on $R$. umbellata growth and morphogenesis, single 1-cm long stem explants without leaves, obtained from adventitious buds, were used. The stem explants were transferred to MS medium supplied with different concentrations of sucrose, fructose, or glucose ranging from 0.003 to $1 \mathrm{M}$. Parameters such as number and length of leaves, number of adventitious buds, fresh and dry weight, percentage of rooting, and number and length of the developed roots were recorded after 4 weeks. All experiments were repeated three times with 30 explants each. 


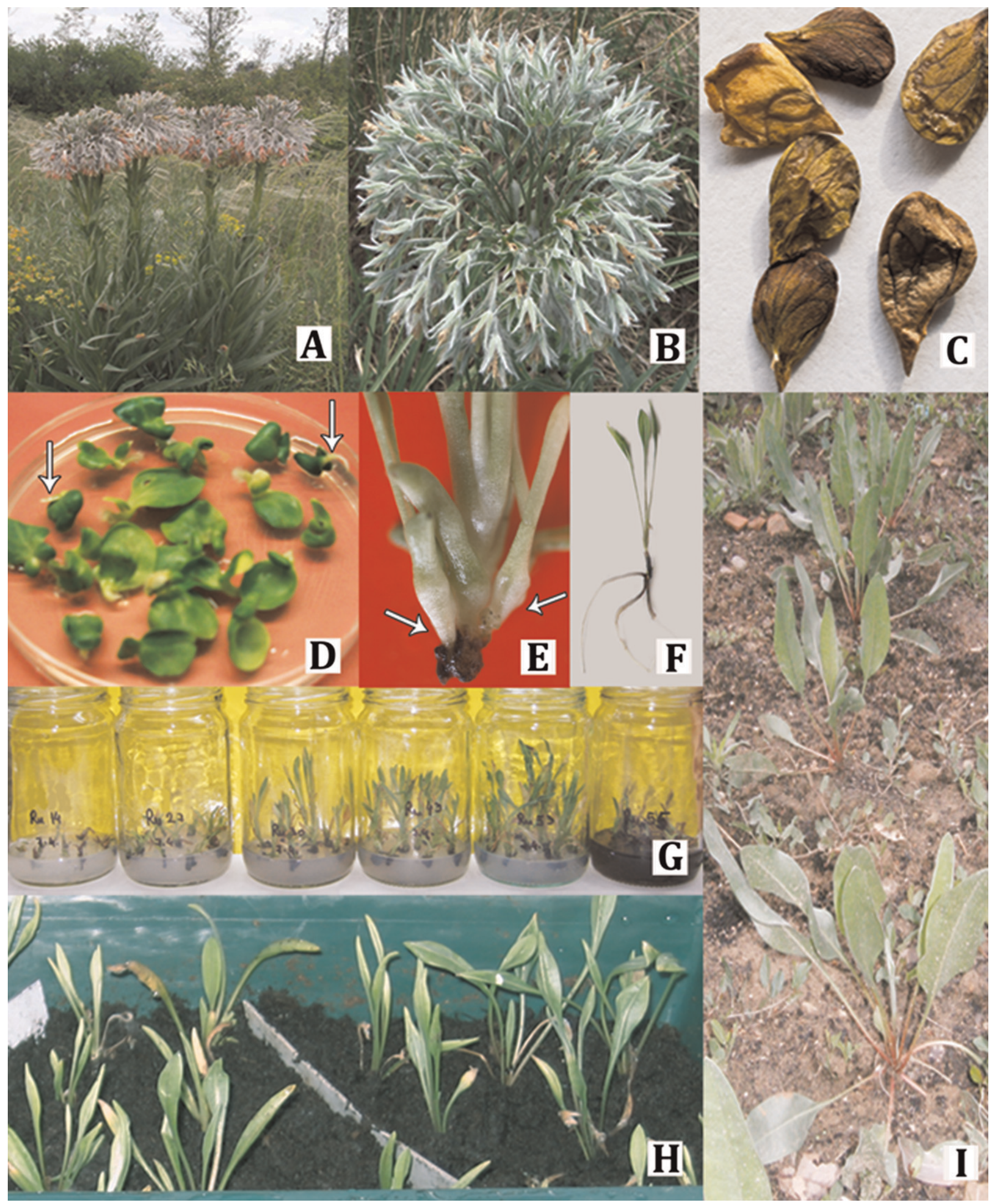

Fig. 1. Rindera umbellata in its natural habitat, in vitro, and acclimated to greenhouse and field conditions. (A) Population of $R$. umbellata in Deliblato Sands, Serbia; (B) inflorescence; (C) seeds; (D) in vitro germination of immature embryos with developed large cotyledons $10 \mathrm{~d}$ after transfer to Murashige and Skoog (MS) medium. Arrows indicate the appearance of radicles; (E) proliferation of adventitious buds on MS medium supplemented with $1 \mathrm{mg} \cdot \mathrm{L}^{-1}$ 6benzylaminopurine, $0.5 \mathrm{mg} \cdot \mathrm{L}^{-1}$ indole-3-acetic acid, and $0.1 \mathrm{~m}$ sucrose after 4 weeks in culture; (F) 4-week-old plant cultured on MS medium with $0.1 \mathrm{M}$ sucrose with developed roots; $(\mathbf{G})$ plants growing on different sucrose concentrations ranging from $0.003 \mathrm{~m}$ to $1 \mathrm{M}$; (H) 2-month-old acclimatized plants in the greenhouse; (I) acclimatized plants growing on the experimental field after 1 year. 
Acclimatization of plantlets to greenhouse and field conditions. The rooted 4-week-old plants that were previously cultured on solid MS were transferred to the greenhouse for acclimatization. Before they were potted in the soil, the plantlets were washed to remove the adhering medium. The soil mixture contained $70 \%$ earthworm compost and $30 \%$ quartz sand. Pots were initially shielded with glass covers to maintain the plants at high humidity. The plantlets were acclimatized by gradually opening the covers. After 2 weeks they were completely uncovered and hardened to the greenhouse conditions. Plants were grown under long-day conditions at $25 \pm 5{ }^{\circ} \mathrm{C}$ temperature and $70 \%$ to $90 \%$ relative humidity. The success of the acclimatization, e.g., the percentage of survival, was recorded 2 months after the transfer of plants to the soil. Two-month-old plants were transferred from the greenhouse to the field in the spring and the survival rate was recorded after 1 year.

Statistical analysis. The significance of differences among the treatments was determined by analysis of variance using STATGRAPHICS software, Version 4.2 (STSC, Inc. and Statistical Graphics Corporation, Orem, UT). Means were compared using the least significant difference multiple range test at a significance level of $P<0.05$. The data are presented as means of pooled results of at least three experiments. The data presented in percentages were subjected to arcsine transformation before the analysis and then converted back to percentages for presentation in a table.

\section{Results and Discussion}

Establishment of in vitro culture from immature embryos. Embryo culture has been used since the early 1940 s to understand the physical and nutritional requirements for embryonic development, to bypass seed dormancy, shorten the breeding cycle, test seed viability, provide material for micropropagation, and rescue immature hybrid embryos from incompatible crosses (Hu and Wang, 1986). In this study the immature $R$. umbellata embryos were used to prevent the loss of seed viability caused by fungal infections. Mycological inspection of the seeds (Fig. 1C) revealed the presence of the destructive pathogen Bipolaris sorokiniana (Ljaljević Grbić et al., 2005). The in vitro culture of immature embryos was established on hormone-free MS medium, where $72 \%$ of the embryos germinated. Large green cotyledons as well as small hypocotyls and roots developed within $7 \mathrm{~d}$ on transfer to MS (Fig. 1D). The formed seedlings grew well on MS medium. When the stem explants were placed on MS supplemented with $1 \mathrm{mg} \cdot \mathrm{L}^{-1} \mathrm{BAP}$ and $0.5 \mathrm{mg} \cdot \mathrm{L}^{-1}$ IAA, all of them formed adventitious buds (the frequency of bud formation was $100 \%$; Table 1) with an average of 5.14 buds per explant as recorded after 4 weeks (Fig. 1E).

Effects of carbon source on in vitro growth and organogenesis of $\mathrm{R}$. umbellata. Speciesspecific carbon source preferences have been determined for a number of culture systems

Table 1. The effect of different carbohydrates on frequencies of adventitious bud formation on isolated stem explants.

\begin{tabular}{lcccc}
\hline $\begin{array}{l}\text { Carbohydrate } \\
\text { concentrations (M) }\end{array}$ & Sucrose & Glucose & Fructose & $\begin{array}{c}1 \mathrm{mg} \cdot \mathrm{L}^{-1} \mathrm{BAP} \text { and } \\
0.5 \mathrm{mg} \cdot \mathrm{L}^{-1} \mathrm{IAA}\end{array}$ \\
\hline 0.003 & $5.02 \pm 2.69 \mathrm{a}$ & $7.16 \pm 2.87 \mathrm{ab}$ & $7.04 \pm 3.02 \mathrm{abc}$ & $/$ \\
0.01 & $7.54 \pm 3.68 \mathrm{ab}$ & $4.29 \pm 2.02 \mathrm{a}$ & $10.02 \pm 2.12 \mathrm{bcd}$ & $/$ \\
0.03 & $6.32 \pm 4.25 \mathrm{ab}$ & $7.18 \pm 3.62 \mathrm{ab}$ & $17.25 \pm 5.52 \mathrm{~d}$ & $/$ \\
0.06 & $38.77 \pm 8.86 \mathrm{~d}$ & $16.15 \pm 8.15 \mathrm{abc}$ & $13.18 \pm 5.06 \mathrm{~cd}$ & 1 \\
0.1 & $18.91 \pm 4.91 \mathrm{bc}$ & $24.60 \pm 6.70 \mathrm{bc}$ & $18.11 \pm 3.37 \mathrm{~d}$ & $100 \pm 0$ \\
0.3 & $22.71 \pm 5.08 \mathrm{c}$ & $27.43 \pm 12.24 \mathrm{c}$ & $2.00 \pm 1.33 \mathrm{ab}$ & $/$ \\
1 & $0 \mathrm{a}$ & $0 \mathrm{a}$ & $0 \mathrm{a}$ & $/$ \\
\hline
\end{tabular}

The data presented are the means of percentage of explants forming adventitious buds \pm SE (50 explants per treatment, repeated three times, $\mathrm{n}=150$ ). The growth regulators BAP and IAA were used only in the phase of culture establishment in combination with $0.1 \mathrm{~m}$ sucrose. Values within each column followed by different letters are significantly different at the $P<0.05$ level according to the least significant difference test. $\mathrm{BAP}=6$-benzylaminopurine; IAA $=$ indole-3-acetacid.

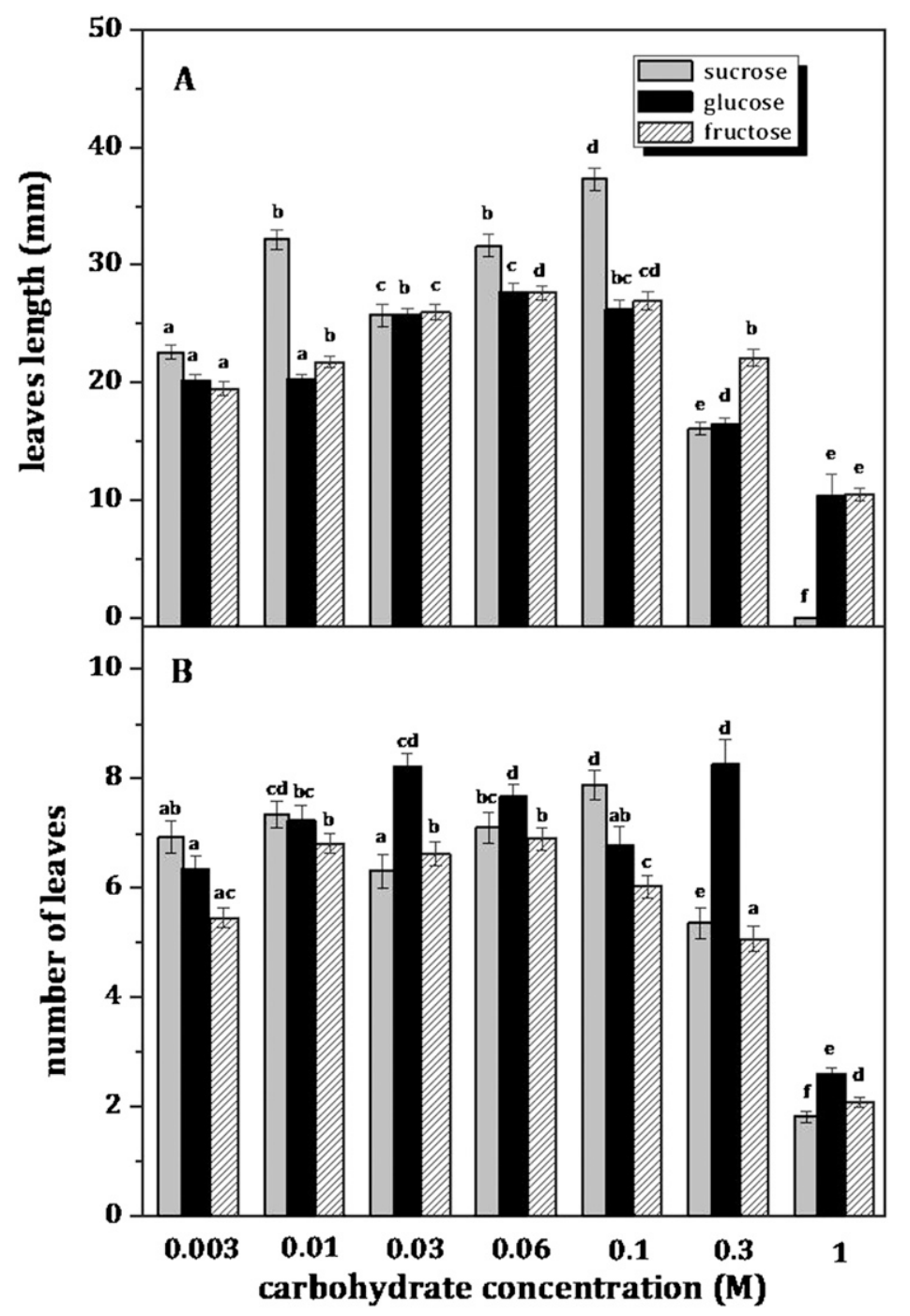

Fig. 2. R. umbellata growth on media supplied with different concentrations of sucrose, glucose, or fructose. After 4 weeks in culture, the lengths of the leaves $(\mathbf{A})$ and the number of leaves in a rosette (B) were recorded. The values presented are means for three replicates with 30 explants each $(n=90)$ with indicated SEs. Statistical difference at the significance level of $P<0.05$ is designated by different letters above the bars, as calculated by least significant difference test for each sugar independently.

(Cuenca and Vieitez, 2000; Harada and Murai, 1996; Mišić et al., 2005; Romano et al., 1995; Welander at al., 1989; Yu and Reed, 1993). It was found that different patterns of morphogenesis were attributable to the type of carbohydrate and its concentration (Millam et al.,
1992; Mukherjee et al., 1991; Ślesak et al., 2004). In vitro growth and development of R. umbellata plants were significantly affected by both the type and concentration of the applied sugars. The number of adventitious buds appearing on stem explants cultured on media 
with different sugar concentrations, but in the absence of growth regulators, was low in comparison with organogenesis on MS with $1 \mathrm{mg} \cdot \mathrm{L}^{-1} \mathrm{BAP}$ and $0.5 \mathrm{mg} \cdot \mathrm{L}^{-1} \mathrm{IAA}$ used for culture establishment, where each explant formed adventitious buds. The highest percentage of explants with developed buds was achieved on $0.06 \mathrm{M}$ sucrose $(38.77 \%)$ or $0.3 \mathrm{M}$ glucose (27.43\%; Table 1).

Varying carbohydrate content of the medium had little effect on the number of leaves in a rosette, except that the highest concentration of any sugar was inhibitory (Fig. 2B). However, increasing concentrations of sugars significantly promoted leaf elongation with sucrose being the most effective (Fig. 2A). Rosettes growing on $0.1 \mathrm{M}$ sucrose had the longest leaves $(37 \mathrm{~mm})$, whereas the optimal concentration of hexoses for leaf elongation was $0.06 \mathrm{M}$ (Fig. 2B). The fresh and dry weight of $R$. umbellata rosettes (Fig. 1G) were also positively correlated with increasing concentrations of sugars up to $0.1 \mathrm{~m}$, but at higher concentrations, the biomass production was reduced (Fig. 3A-B). The sucrose-containing media were superior to those with hexoses. The optimal sucrose concentration of $0.1 \mathrm{M}$ resulted in fresh weight increase of $0.21 \mathrm{~g}$ as recorded after 4 weeks.

The highest percentage of explants with roots $(65 \%)$ was recorded for a medium supplemented with $0.1 \mathrm{M}$ sucrose, whereas fructose and glucose were less effective, supporting up to $30.83 \%$ and $22.5 \%$ rooting, respectively (Fig. 4A). The length and the number of the roots were highest on sucrose and lowest on glucose-supplemented media (Fig. 4B-C). The optimal sucrose concentration for both parameters was $0.1 \mathrm{M}$. The majority of the roots were formed after 3 weeks (data not shown). A rooted plantlet is shown in Figure 1F.

The capacity of a plant tissue or an explant to use specific carbohydrates depends on its absorbing ability and metabolic competence (Mezzetti et al., 1991), whereas the optimal sugar concentration is determined by basic carbon/energy requirements at lower concentrations and osmotic stress imposed by higher concentrations. For all of the observed processes or parameters, sucrose $(0.1 \mathrm{M})$ proved to be the best carbon source, whereas glucose was more effective than fructose for most recorded parameters, except for rooting. Concentrations of sucrose over $0.1 \mathrm{M}$ (or over $0.06 \mathrm{M}$ for hexoses) imposed an osmotic stress as judged by comparison of dry to fresh weight of the rosettes (Fig. 3C). The fact that $R$. umbellata explants survived and grew on any of the offered sugars means that the explant tissues are metabolically competent to use them efficiently. Although all sugars (at equimolar concentrations) have equal osmotic contributions to the medium, sucrose has higher caloric value in comparison with hexoses, which explains why it is preferred as a carbon source for $R$. umbellata growth.

Acclimatization to greenhouse and field conditions. The 4-week-old and well-rooted $R$. umbellata plantlets, obtained on medium with $0.1 \mathrm{M}$ sucrose, were transferred to the soil. Their acclimatization to the greenhouse

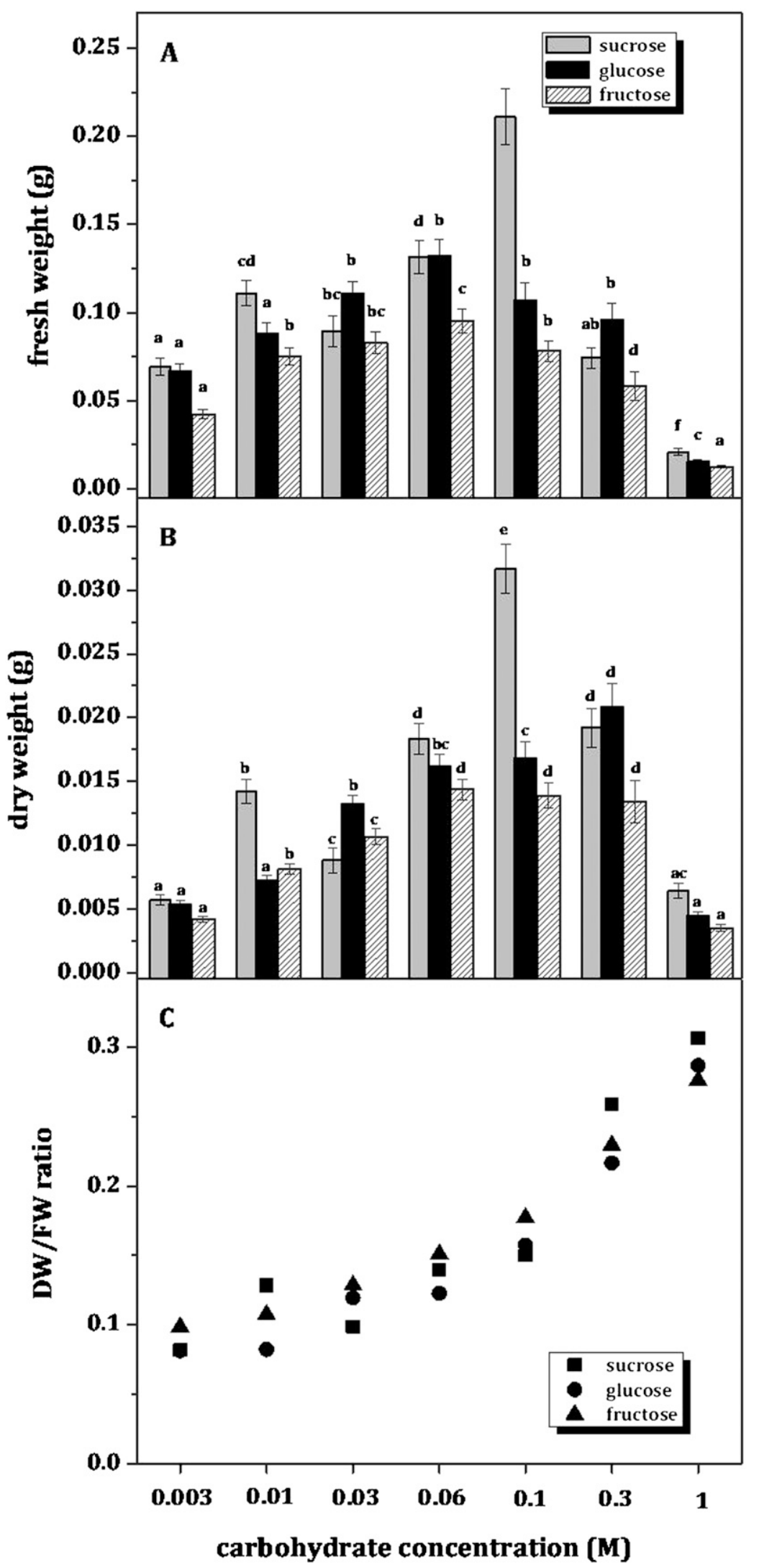

Fig. 3. Biomass production of $R$. umbellata plants grown on media supplied with different concentrations of sucrose, glucose, or fructose. Fresh (A) and dry weight (B) of the rosettes were recorded after 4 weeks in culture. (C) The ratio of dry to fresh weight of the rosettes for each sugar, indicating tissue dehydration at higher sugar concentrations. The values presented are means for three replicates with 30 explants each $(\mathrm{n}=90)$ with indicated sEs. Statistical difference at the significance level of $P<0.05$ is designated by different letters above the bars, as calculated by least significant difference test for each sugar independently. 


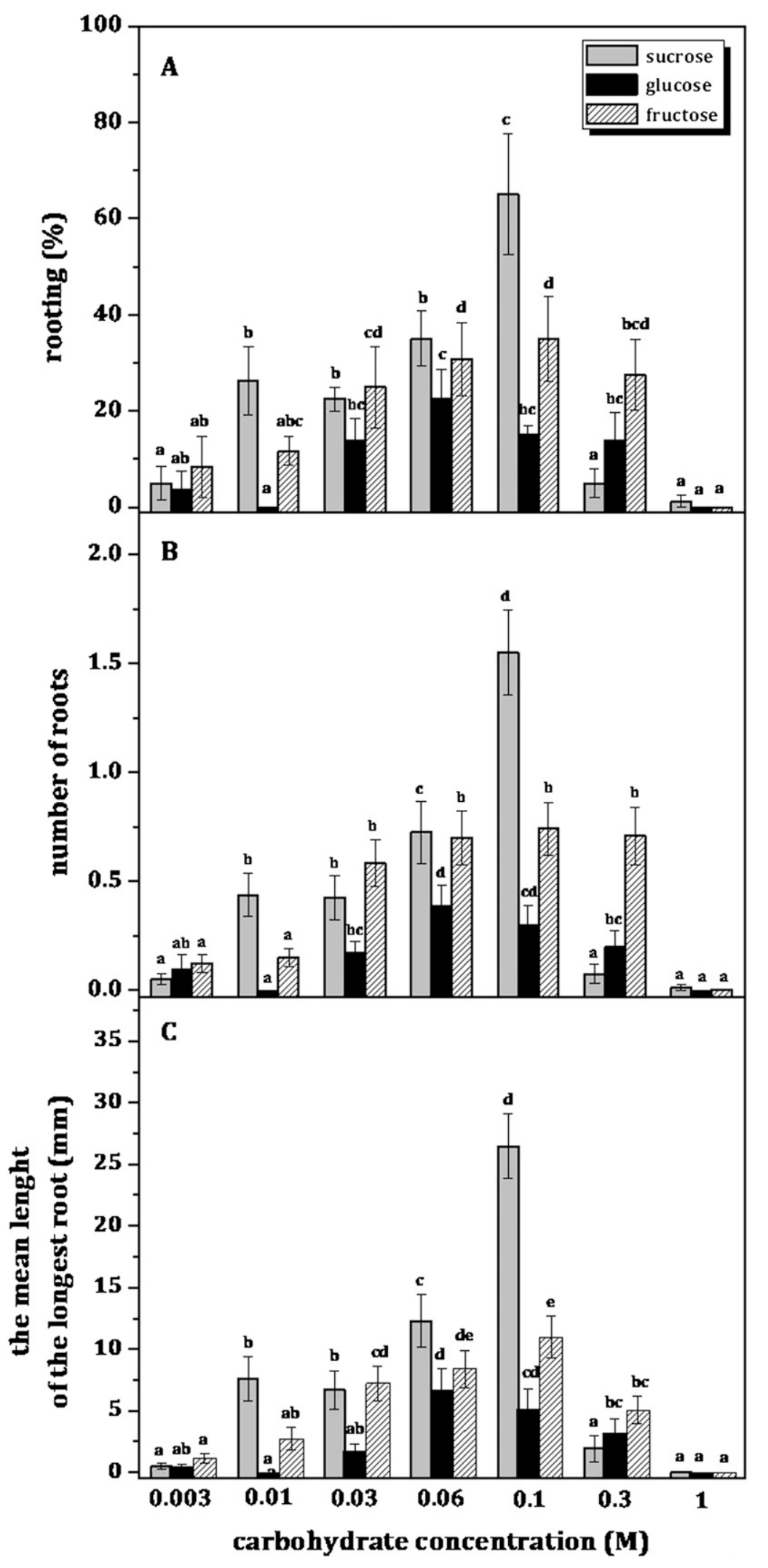

Fig. 4. Effects of carbohydrate type and concentration on rooting of $R$. umbellata plantlets. Plants were grown on media containing sucrose, glucose, or fructose and rooting parameters including the percent of rooted plantlets $(\mathbf{A})$, the number of roots per plant $(\mathbf{B})$, and the length of the longest root $(\mathbf{C})$ were recorded after 4 weeks. Values are the means of three replicates with 30 explants each $(n=90)$ with indicated SEs. For each sugar, the values with the different letters are significantly different at the $P<0.05$ level according to the least significant difference test. conditions was successful with a survival rate of $100 \%$ after 2 weeks and $71.43 \%$ after 2 months, so the critical step for ex vitro survival and preservation of this endangered species has been efficiently overcome. The acclimatized plants were normal without any morphological abnormalities or variations (Fig. 1H). Supplementation of sugars to culture media helps in the maintenance of osmotic potential of the cells and conservation of water (Hazarika, 2003), which is important for ex vitro settlement of the plants (Van Huylenbroeck et al., 2000). Exogenous supply of sugars increases starch and sucrose reserves in in vitro-growing plants that could favor ex vitro acclimatization and speed up the physiological adaptations (Pospísilová et al., 1999). Langford and Wainwright (1987) found that sucrose supplied at a concentration of $3 \%$ $(\approx 0.1 \mathrm{M})$ in the medium increased the photosynthetic ability, thereby improving survival of rose plantlets. Additionally, Jo et al. (2009) have demonstrated that in vitro preconditioning of Alocasia amazonica plantlets with 3\% sucrose is advantageous for ex vitro survival and acclimatization. Thus, the successful acclimatization of the sucrose-treated $R$. umbellata plantlets to the greenhouse conditions is in accordance with the literature data. The acclimatized plants were then successfully transferred to the field (Fig. 1I), where $42.86 \%$ of the plants survived after 1 year.

In conclusion, an efficient protocol has been developed for in vitro growth of $R$. umbellata by germination of immature embryos and induction of multiple adventitious buds by growth regulators completed with a high-frequency rooting and acclimatization protocol. This plant regeneration system could be useful for conservation programs to preserve this critically endangered species. Moreover, obtaining enough genetically uniform plant material under controlled growth conditions may be valuable for pharmacological and metabolomic studies.

\section{Literature Cited}

Cuenca, B. and A.M. Vieitez. 2000. Influence of carbon source on shoot multiplication and adventitious bud regeneration in in vitro beech cultures. Plant Growth Regulat. 32:1-12.

Diklić, N., M. Niketić, and G. Tomović. 1999 Crvena Knjiga Flore Srbije 1 Iščezli I krajnje ugroženi taksoni, p. 251-479. In: Stevanović, V. (ed.). Ministarstvo za životnu sredinu Republike Srbije, Biološki fakultet Univerziteta u Beogradu, Zavod za zaštitu prirode Republike Srbije, Beograd [in Serbian].

Harada, H. and Y. Murai. 1996. Micropropagation of Prunus mume. Plant Cell Tiss. Org. Cult. 46: $165-167$.

Hazarika, B.N. 2003. Acclimatization of tissuecultured plants. Curr. Sci. 85:1704-1712.

$\mathrm{Hu}, \mathrm{C}$. and P. Wang. 1986. Embryo culture: Technique and applications, p. 43-96. In: Evans, D.A., W.R. Sharp, and P.V. Ammirato (eds.). Handbook of plant cell culture. Vol. 4. Macmillan, New York, NY.

Jo, E.A., R.K. Tewari, E.J. Hahn, and K.Y. Peak. 2009. In vitro sucrose concentration affects growth and acclimatization of Alocasia amazonica plantlets. Plant Cell Tiss. Org. Cult. 96:307-315. 
Kozai, T. 1991. Micropropagation under photoautotrophic conditions, p. 447-469. In: Debergh, P.C. and R.H. Zimmerman (eds.). Micropropagation technology and application. Kluwer Academic Publishers, Dordrecht, The Netherlands.

Langford, P.J. and H. Wainwright. 1987. Effect of sucrose concentration on the photosynthetic ability of rose shoots in vitro. Ann. Bot. (Lond.) 60:633-640

Ljaljević Grbić, M., J. Vukojević, J. Glamočlija, D. Janošević, D. Grubišić, and A. Mijović. 2005. Gljive na ugroženim i retkim biljkama. 8th Symposium on the flora of Southeastern Serbia and Neighbouring Regions, Book of Abstracts, Niš. p. 23 [in Serbian].

Mezzetti, B., L.S. Coute, and P. Rosati. 1991. Actinidia deliciosa in vitro II. Growth and exogenous carbohydrate utilisation by explants. Plant Cell Tiss Org. Cult. 26:153-160.

Millam, S., D. Davidson, and W. Powell. 1992. The use of flax (Linum usitatissimum) as a model system for studies on organogenesis in vitro: The effect of different carbohydrates. Plant Cell Tiss. Org. Cult. 28:163-166.

Mišić, D., V. Maksimović, S. Todorović, D. Grubišić, and R. Konjević. 2005. Influence of carbohydrate source on Nepeta rtanjensis growth, morphogenesis and nepetalactone production in vitro. Isr. J. Plant Sci. 53:103-108.
Mohamed, M.A.-H. and A.A. Alsadon. 2010. Influence of ventilation and sucrose on growth and leaf anatomy of micropropagated potato plantlets. Sci. Hort. 123:295-300.

Mukherjee, S.K., B. Rathinasabapathi, and N. Gupta. 1991. Low sugar and osmotic requirements for shoot regeneration from leaf pieces of Solanum melongena L. Plant Cell Tiss. Org. Cult. 25:13-16.

Murashige, T. and F. Skoog. 1962. A revised medium for rapid growth and bioassays with tobacco tissue culture. Physiol. Plant. 15:473-497.

Nowak, B., K. Miczyński, and L. Hudy. 2004. Sugar uptake and utilization during adventitious bud differentiation on in vitro leaf explants of 'Wegierka Zwykta' plum (Prunus domestica). Plant Cell Tiss. Org. Cult. 76:255-260.

Papageorgiou, V.P., A.N. Assimopoulou, and A.C. Ballis. 2008. Alkannins and shikonins: A new class of wound healing agents. Curr. Med. Chem. 15:3248-3267.

Pospíšilová, J., I. Tichá, P. Kadleček, D. Haisel, and Š. Plzáková. 1999. Acclimatisation of micropropagated plants to ex vitro conditions. Biol. Plant. 42:481-497.

Rolland, F., E. Baena-Gonzalez, and J. Sheen. 2006. Sugar sensing and signaling in plants: Conserved and novel mechanisms. Annu. Rev. Plant Biol. 57:675-709.

Romano, A., C. Noronha, and M.A. Martins-Loucao. 1995. Role of carbohydrates in micropropagation of cork oak. Plant Cell Tiss. Org. Cult. 40: 159-167.

Sghaier, B., W. Kriaa, M. Bahloul, J.V.J. Novo, and N. Drira. 2009. Effectof ABA, arginine and sucrose on protein content of date palm somatic embryos. Sci. Hort. 120:379-385.

Ślesak, H., A. Skoczowski, and L. Przywara. 2004. Exogenous carbohydrate utilisation by explants of Brassica napus cultured in vitro. Plant Cell Tiss. Org. Cult. 79:45-51.

Smeekens, S. 2000. Sugar-induced signal transduction in plants. Annu. Rev. Plant Physiol. Plant Mol. Biol. 51:49-81.

Todorović, S., D. Grubišić, Z. Giba, D. Mišić, and R. Konjević. 2006. Sucrose effects on in vitro fruiting and seed production of Centaurium pulchellum. Biol. Plant. 50:771-774.

Van Huylenbroeck, J.M., A. Piqueras, and P.C. Debergh. 2000. The evolution of photosynthetic capacity and the antioxidant enzymatic system during acclimatization of micropropagated Calathea plants. Plant Sci. 155:59-66.

Welander, M., N.T. Welander, and A.S. Brackman. 1989. Regulation of in vitro shoot multiplication in Syringa, Alnus and Malus by different carbon sources. J. Hort. Sci. 64:361-366.

$\mathrm{Yu}$, X. and B.M. Reed. 1993. Improved shoot multiplication of mature hazelnut (Corylus avelana L.) in vitro using glucose as a carbon source. Plant Cell Rpt. 12:256-259. 